\title{
Geomechanical Risks in Coal Bed Carbon Dioxide Sequestration
}

\author{
Larry R. Myer \\ Lawrence Berkeley National Laboratory. Earth Sciences Division, Berkeley, CA 94720
}

\section{INTRODUCTION}

The purpose of this report is to summarize and evaluate geomechanical factors which should be taken into account in assessing the risk of leakage of $\mathrm{CO}_{2}$ from coal bed sequestration projects. The various steps in developing such a project will generate stresses and displacements in the coal seam and the adjacent overburden. The question is whether these stresses and displacements will generate new leakage pathways by failure of the rock or slip on pre-existing discontinuities such as fractures and faults.

In order to evaluate the geomechanical issues in $\mathrm{CO}_{2}$ sequestration in coal beds, it is necessary to review each step in the process of development of such a project and evaluate its geomechanical impact. A coal bed methane production/ $/ \mathrm{CO}_{2}$ sequestration project will be developed in four steps:

- Drilling and completion of wells

- Formation dewatering and methane production

- $\mathrm{CO}_{2}$ injection with accompanying methane production

- Possible $\mathrm{CO}_{2}$ injection for sequestration only

The approach taken in this study was to review each step: Identify the geomechanical processes associated with it, and assess the risks that leakage would result from these processes. 


\section{DRILLING AND COMPLETIONS RISKS}

\section{Drilling Issues}

Wellbore stability is a geomechanical problem which can be encountered during drilling of the well. Weak shale layers, weak coal layers, overpressure, and faults zones are common causes. Rock failure and displacements associated with wellbore instability generate potential leakage paths in the vicinity of the well. The risk of leakage will be minimized by cementing the casing. It is conventional practice to place cement behind production casing, and the depth over which it is placed is subject to state regulations.

Title 19 chapter 15 of the New Mexico Administrative Code states "cement shall be placed throughout all oil-and gas-bearing zones and shall extend upward a minimum of 500 feet above the uppermost perforation or, in the case of open-hole completion 500 feet above the production casing shoe".

Alabama's regulations specific to coalbed methane operations have been used by other states as a model. Section 400-3 of the Rules and Regulations of the State Oil and Gas Board of Alabama states that the casing shall be cemented for 200 feet above the top of the uppermost coalbed which is to be completed, or for 200 feet above the production casing shoe in open hole completions. The production interval in cased hole completions need not be cemented.

When a coalbed methane project is converted to $\mathrm{CO}_{2}$ sequestration, $\mathrm{CO}_{2}$ will be injected under pressure. Wells used for injection in oil and gas formations are subject to additional regulations requiring periodic testing for leakage in the cased section. The type of testing which is required is set by individual states. In New Mexico, these tests can include the use of tracers to test for leakage in the annulus.

Injection of $\mathrm{CO}_{2}$ also increases the risk of leakage in the annulus between casing and formation due to chemical dissolution of the cement. Experience in enhanced oil recovery has lead to development of additives for cement used for $\mathrm{CO}_{2}$ injectors. This experience should be applicable to coal bed methane $\mathrm{CO}_{2}$ projects. 
If old production wells or idle wells are used for $\mathrm{CO}_{2}$ injection there is a risk that leakage paths may be present in the annular space between the casing and the rock due to deteriorated or missing cement. Casing bond logs and tracer tests can be used to evaluate the integrity of the cement in the annulus or the contact between casing and formation. If it is found that leaks may occur, cement can be injection (squeezed) into the annulus. However, the process of seal formation in the annulus by cement squeeze behind casing is expensive and often only partially successful.

Because of the importance of the casing cement in minimizing the risk of $\mathrm{CO}_{2}$ leakage, additional work should be directed toward development of recommendations for best practices. In particular, criteria for setting the height of the cement behind casing needs further study. Because of the substantial industry experience in water flooding and $\mathrm{CO}_{2}$ enhanced oil recovery, a case history study of the performance of production casing cement would provide valuable data for a best practices study.

\section{Conventional Completions}

A conventional completion for a coal bed methane project involves perforating or slotting the casing in

the coal seam (Figure 1). Since the permeability of coal matrix is low, hydrofracturing is used to enhance permeability during dewatering and primary production. If the project is converted to $\mathrm{CO}_{2}$ enhanced recovery and sequestration, pre-existing hydrofractures will enhance the injectivity of the $\mathrm{CO}_{2}$. However, the risk of $\mathrm{CO}_{2}$ leakage is also increased if hydrofractures extend into the overburden. Growth into the overburden can happen when the hydrofracture is initially created. Since $\mathrm{CO}_{2}$ is injected under pressure, there is risk that growth into the overburden could also occur during the enhanced recovery and sequestration phases of the project. 


\section{Cased Hole}

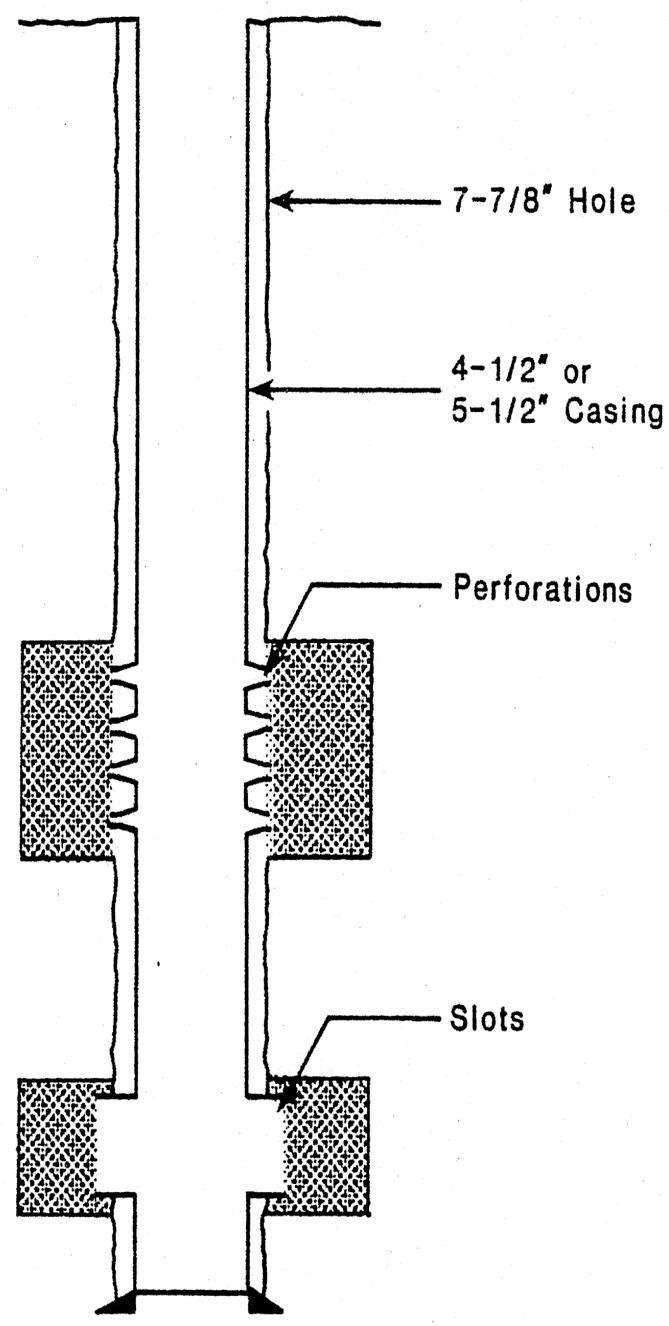

Drill through coals

Cement casing across coals Access coals

Fracture stimulate through damage

Figure 1. Schematic diagram of core hole completion for coal bed methane well (after Murray 1993)

\section{Openhole Cavity}

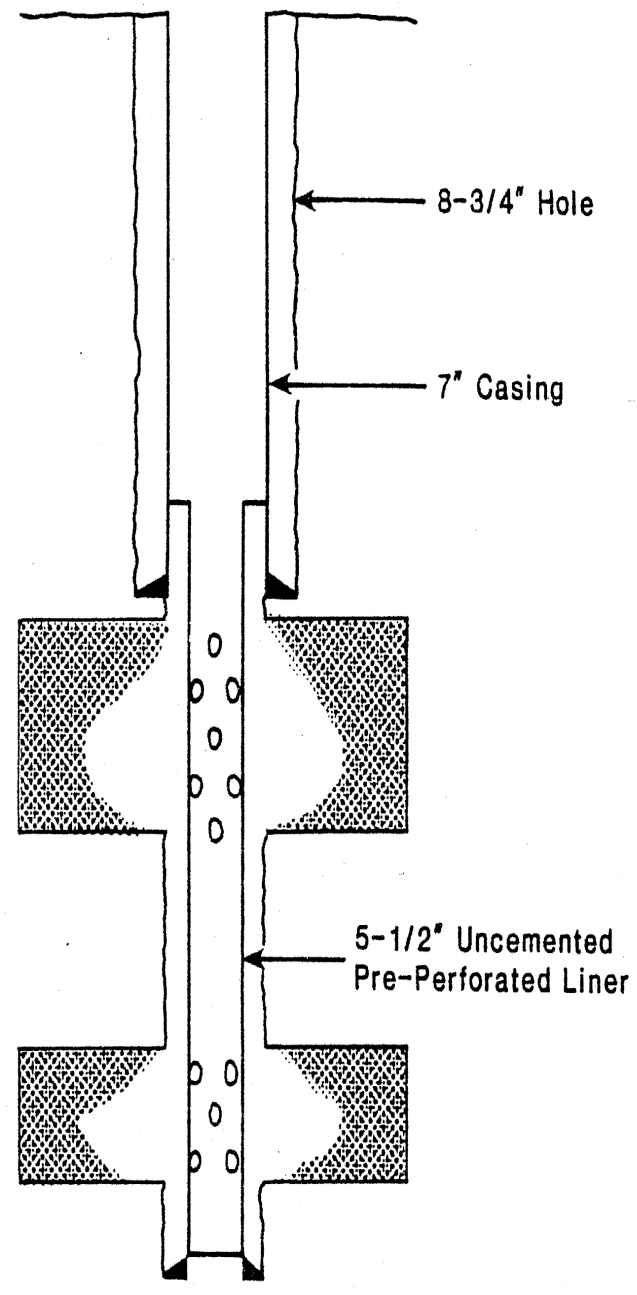

Place cemented casing above coals Drill through coals "underbalanced". Create cavity

Place uncemented pre-perforated liner

Figure 2. Schematic diagram of cavity completion for coal bed methane well. (after Murray 1993) 
The potential for vertical extension of a hydraulic fracture is dependent upon several factors (Ben-Naceur 1989):

- In-situ stress state

Higher horizontal stress in surrounding layers will impede vertical fracture growth, while lower horizontal stress tends to accelerate it. Higher pore pressure will enhance fracture growth. On average, horizontal stress increases with depth due to gravity but it is known that lithology can affect in-situ stress values. Pore pressures can also depart significantly from a "normal" hydrostatic gradient depending on numerous natural hydrostratigraphic conditions as well as previous production and injection activities in the field.

- Elastic moduli

Vertical growth is impeded if the adjacent layer is stiffer than the coal seam. This is most likely to be the case if limestone or sandstone are the bounding strata. Siltstones and shale can vary widely in properties, but many are also stiffer than coals.

- Toughness

Higher fracture toughness will impede fracture growth. For large fractures, tensile strength is not a major factor (Ben-Naceur 1989). The fracture toughness of coal is not well known. Atkinson and Meredith (1987) compiled results of tests on four different coals. For Latrobe Valley Brown and Pittsburgh coal, values of "stress intensity resistance" ranged from $0.006 \mathrm{MPam}^{1 / 2}$ to $0.063 \mathrm{MPam}^{1 / 2}$. However, for Queensland semi-anthracite and New South Wales black coal, values ranged from 0.13 $\mathrm{MPam}^{1 / 2}$ to $0.44 \mathrm{MPam}^{1 / 2}$. For comparison, values for sandstone, shale and limestone ranged from about $0.4 \mathrm{MPam}^{1 / 2}$ to $1.7 \mathrm{MPam}^{1 / 2}$, with values for limestone generally being higher. This data indicates that some coals will have significantly lower fracture toughness than typical bounding formations, and, therefore, low risk of fracture growth out of interval. 
- Leakoff

High fluid loss in the bounding layer will retard growth of a fracture propagating into it.

- Fluid flow

Vertical fracture propagation will also be affected by the vertical component of fluid flow, which is affected by fracture opening and fluid properties. Non-Newtonian fracture fluids can have significant impacts on fracture growth. Carbon dioxide is normally modeled on a Newtonian fluid. However, it will generally be in the non-wetting phase. The effects of the fluid properties of $\mathrm{CO}_{2}$ (particularly the non-wetting characteristics) on fracture propagation are a topic for further research.

Linear elastic fracture mechanics models have been developed to predict vertical fracture growth (see Ahmed 1989 for summary). Ahmed et al (1985) developed expressions specifically for design in multiple zones. The approach is to first calculate the stress intensity factors for the top and bottom of the fracture. The stress intensity factor is a function of the height of the fracture the in-situ horizontal effective stress, and the fluid pressure in the fracture. Fracture growth is predicted when the stress intensity factor exceeds a critical value given by the fracture toughness of the rock.

Risk of leakage will be reduced if the vertical extent of hydrofractures can be monitored. In cased wells measurement of fracture height, or detection of vertical propagation into bounding formations, is a challenging undertaking. Ahmed 1989, and Anderson et al 1986, describes the use of radioactive tracers in conjunction with gamma ray logging. However, this technique only provides information in the near wellbore region.

In principle, seismic methods could be used to monitor the extension of a hydrofracture. Passive seismic techniques use seismic "events" generated by the fracturing process to locate the fracture. The fracture 
can also be imaged by a number of active seismic techniques. Though field experiments have been conducted, there is as yet no generally accepted seismic technique for determining fracture height. Nolte and Economides (1989) describe a method for interpreting the downhole pressure decline during pumping to determine if a fracture has propagated into a bounding layer. Pressure analyses are complicated by a number of factors which influence the pressure response.

\section{Open Cavity Completions}

A second type of completion for coal bed methane projects is the open hole cavity method (Figure 2). This technique was developed in the San Juan basin and is advantageous in areas where reservoir pressures are higher than normal. In such areas, casing is set above the coal seam and a cavity is generated by one of two methods (Bland 1992). The first method is to drill through the coal seam underbalanced with water, air or foam. The excess formation pressure causes the coal to collapse into the wellbore. The coal is removed by displacing with drilling fluid and a perforated screen is set.

The second method uses pressure surges to collapse the coal. The well is shut in to build up pressure and then is abruptly released. Collapsed coal is then removed. This process can be repeated several times until the coal no longer collapses. Bland (1992) reported that the effect could extend as much as $100 \mathrm{~m}$ into the coal seam.

Creation of a cavity can potentially cause failure and displacements in the overlying strata which provide pathways for $\mathrm{CO}_{2}$, and increase the risk of leakage. Factors which influence the amount of disturbance in the overburden include the size and shape of the cavity, surge pressures, depth and in-situ stress, layer thickness, rock strength and degree of natural fracturing in the overburden.

The process of pressure surging sets up high pore pressure gradients in the rock and corresponding flow lines as schematically illustrated in Figure 3a. Underbalanced drilling has the same affect though the pore 
pressure gradients would be lower. These pressure gradients cause fractures, joints, and cleats oriented perpendicular to the flow lines to open, leading to sloughing of the coal into the opening. The pressure gradients are also present in the overburden, so there is risk that this rock will also collapse into the cavity. The risk is highest for weak, thinly bedded, highly fractured shale. The risk is least for massively bedded sandstone and limestone. 
a)

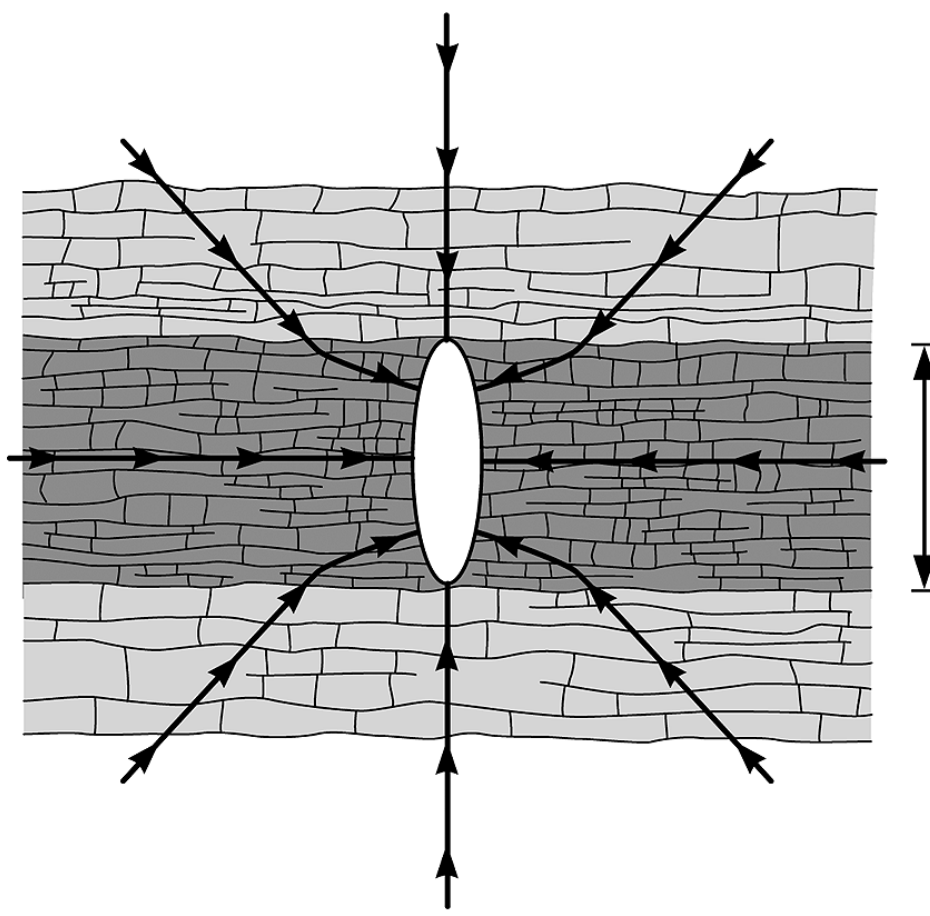

coal bed

b)
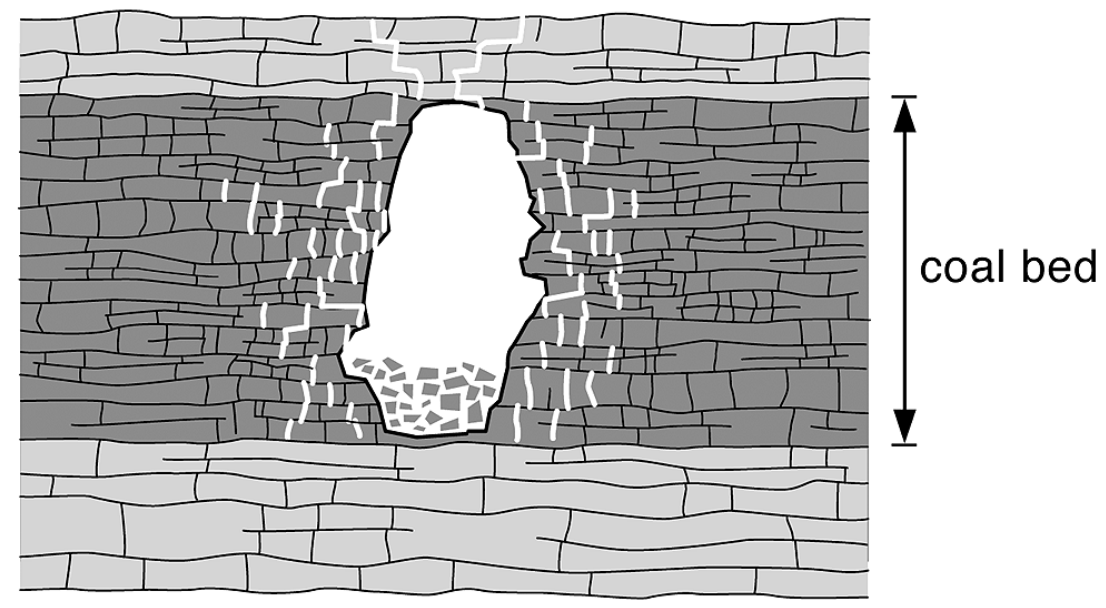

Figure 3. Schematic illustration of rock mass behavior associated with cavity completions in coal beds;

a) Flow lines for water movement during surging

b) Growth of cavity and fracturing in the coal and overburden

The risk of overburden collapsing into the cavity increases as the cavity grows in width. As shown in

Figure 3b, removal of coal results in an unsupported span of layered overburden. As the span increases, so does the likelihood of finding fractures which define blocks. These blocks can be moved or removed by repeated surging. Since the interfaces between rock layers are weak, repeated surging would also tend to cause separation between layers producing more fluid pathways. 
Creation of a cavity also results in a redistribution of the in-situ stresses. This redistribution is very dependent upon the shape of the cavity as well as the relative magnitude of the vertical and horizontal far field stresses. The shape of the cavity formed by surging can be approximated by an ellipsoid with major axis equal to the thickness of the seam. The stress distribution around an elliptical (2-D) cavity with major axis oriented parallel to the vertical far field stress is shown in Figure 4. It is seen that near the opening, in a direction along the minor axis the horizontal stress is less than the far field stress. Thus the stress redistribution would be acting to further open fractures already opened by pressure surging. Similarly, along the major axis the vertical stress is less than the far field, increasing the risk that pressure surges would cause bedding plane partings.

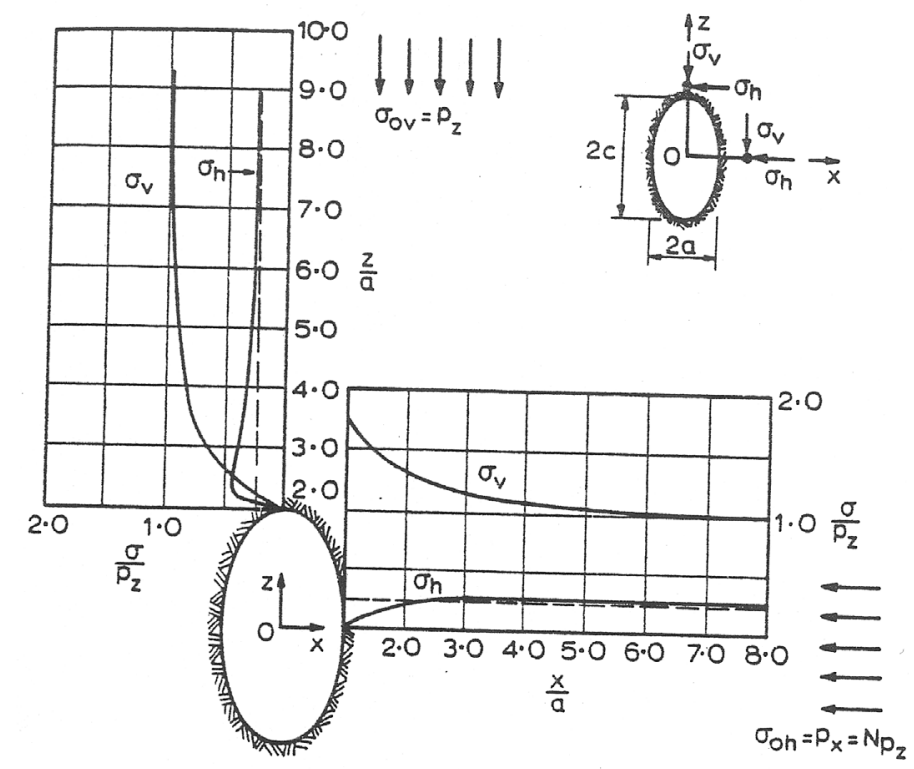

Figure 4. Stresses around an elliptical cavity $(\mathrm{a} / \mathrm{c}=1 / 2)$ in homogeneous stress fields $(\mathrm{N}=0.25)$ (Poulos and Davis, 1974, from Terzaghi and Richart, 1952)

\section{PRODUCTION AND REPRESSURIZATION RISKS}

The pore pressure reductions which occur during dewatering and methane production and pore pressure increase which occur during $\mathrm{CO}_{2}$ injection, cause displacements in the reservoir and surrounding rock. A 
conservative assumption (to be discussed further) is that leakage will result if the rock fails or if slip occurs on pre-existing faults or discontinuities.

\section{Failure and Slip in a Coal Seam}

A convenient way of assessing the potential for failure or slip is the Mohr diagram (Figure 5). A simple two-dimensional linear Mohr-Coulomb failure criterion is shown for illustration. The effective principal stress defined as total stress minus pore pressure is plotted on the horizontal axis and referred to as "normal stress". It is commonly assumed that an increase in pore pressure in the reservoir has an equal effect on both components of principal stress, causing the Mohr circle to shift to the left, closer to failure, that is, from $\mathrm{I} \rightarrow \mathrm{II}$ in Figure 5. This assumption has been employed in previous assessments of the potential for fault slip due to reservoir pressurization by $\mathrm{CO}_{2}$ injection (Gibson-Poole et al, 2002). If pore pressures are reduced, it follows from this model that both components of effective stress would be increased by the same amount, moving the Mohr circle away from failure.

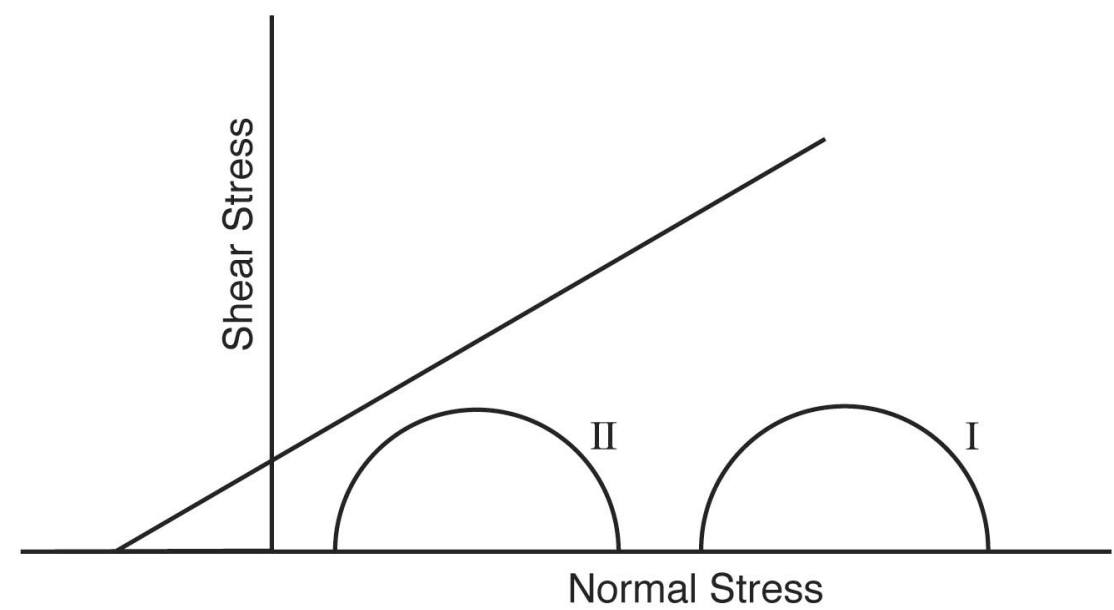

Figure 5. Mohr circles for initial (I) and final (II) stress state when it is assumed that a pore pressure increase affects both principal stresses equally.

Observations in a number of petroleum reservoirs (Addis, $1997 \mathrm{a}, \mathrm{b}$ ) have shown that the reduction in pore pressure due to production causes a smaller change in horizontal stress than in vertical stress. The effect on the potential for failure is shown in Figure 6. Since pore pressures are decreasing, the Mohr 
circle moves to the right. However, since the change in horizontal effective stress is less than in the vertical effective stress, the circle actually gets closer to failure that is from $\mathrm{I} \rightarrow \mathrm{III}$ in Figure 6 . Teufel, et al, 1991, showed that these effects were large enough to cause failure of the high porosity chalk in the North Sea Ekofisk reservoir. Streit and Hillis, 2002, further analyzed the effects on fault slip.

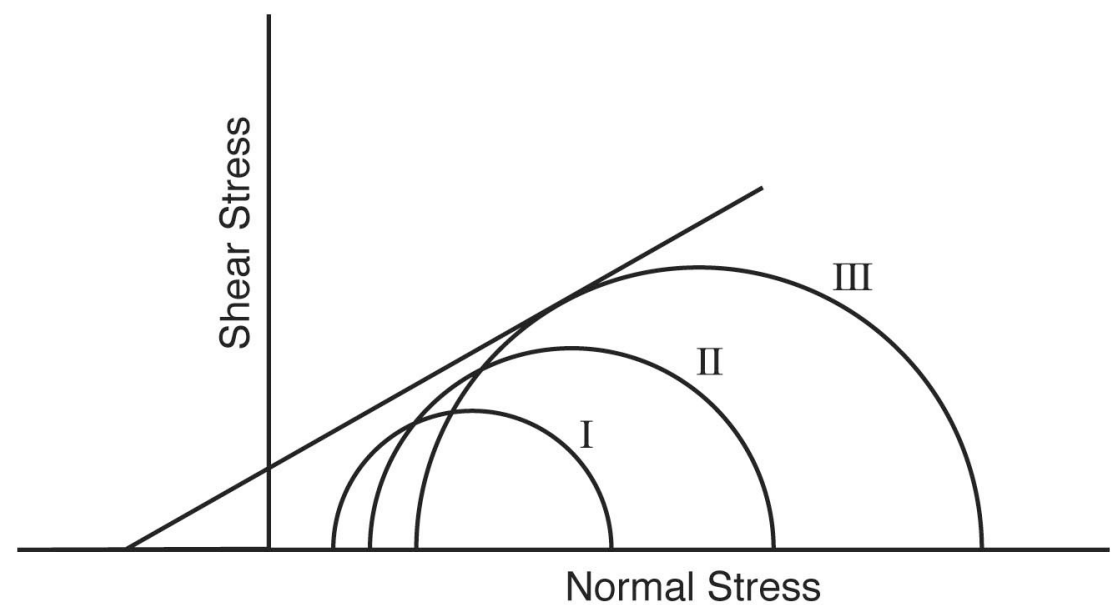

Figure 6. Mohr circles for initial (I), intermediate (II), and final (III) stress states for pore pressure reduction assuming that horizontal stresses are less affected than vertical stresses. Failure or slip occurs at III.

These relative changes in horizontal and vertical effective stresses are the result of the effects of far field (in-situ) boundary conditions and poroelastic properties of the rock. Figure 7 shows that the rate of change in horizontal stress with pore pressure, i.e. $\Delta \sigma_{\mathrm{h}} / \Delta \mathrm{P}$ where $\sigma_{\mathrm{h}}$ is horizontal stress and $\mathrm{P}$ is pore pressure, decreases as Poisson's Ratio of the reservoir rock increases. Touloukian and Ho, 1981, report measured values of Poisson's Ratio for coal of 0.2 to 0.4 . 


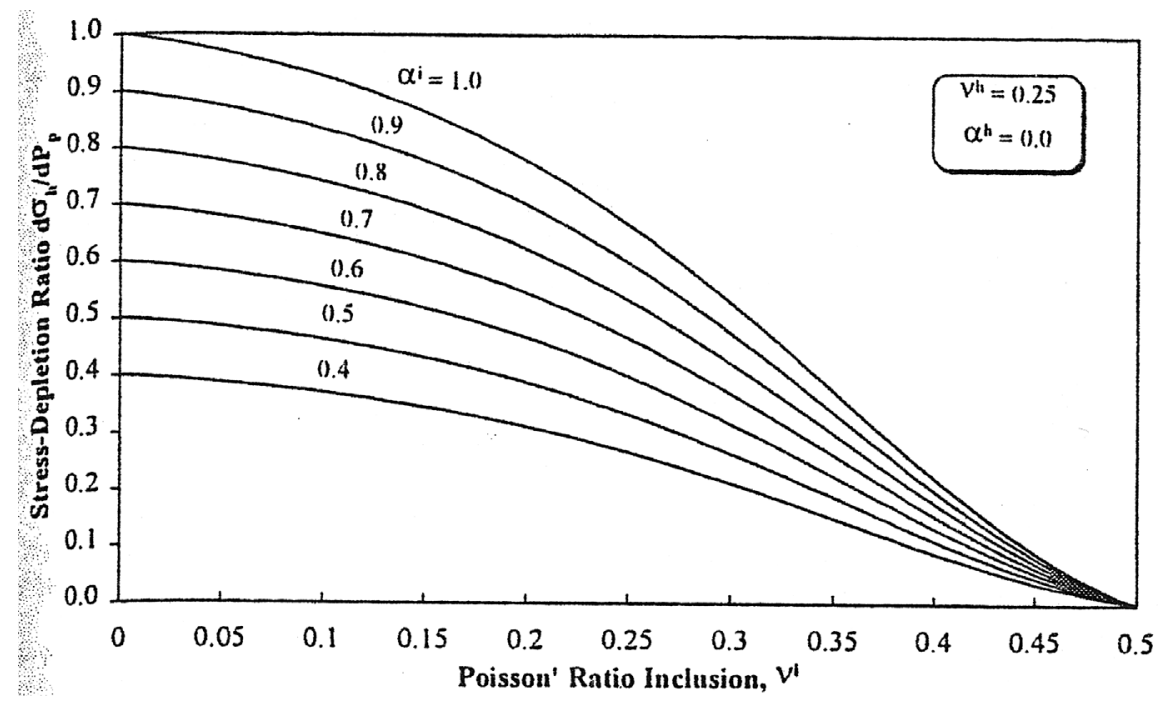

Figure 7. Effect of Poisson's ratio of the reservoir rock on rate of change in horizontal stress with pore pressure for a disc-shaped reservoir modeled as an inclusion (i) in a host (h) rock. Different curves show influence of value of Biot coefficient (from Addis et al, 1998).

The risk of failure or slip in the coal will depend on depth, in-situ stress state, pressure drawdown, and coal strength and poroelastic properties. Conditions which result in large principal stress differences increase the risk of failure and slip. Tectonic activity will result in increased differential far field stresses. Large pore pressure drawdown will increase differential stress. Risk of failure increases for low strength coal. In-situ stresses increase with depth, but the strength of rock increases with level of confinement. The risk of failure may or may not increase with depth depending on the amount of pore pressure drawdown and the magnitude of differences between components of in-situ stress. The risk of slip on pre-existing discontinuities is increased for low cohesion and low frictional sliding resistance.

Injection of $\mathrm{CO}_{2}$ for enhanced methane production and sequestration will increase pore pressures in the coal seam. In a poroelastic system effective stress changes due to pore pressure drawdown are simply reversed by pore pressure increase due to injection. Thus, a Mohr circle which had moved closer to failure under drawdown would move farther from failure during injection until the original, pre-development pore pressures are obtained. Failure, however, is an inelastic process and, in general, results in a complex redistribution of stress in the system. 
If pore pressures from $\mathrm{CO}_{2}$ injection exceed pre-development levels, then there is a risk that slip will occur even though it had not occurred under drawdown conditions. This is conceptually illustrated in Figure 8, where the Mohr circle for pre-development stress state is labeled I. Dewatering and methane production moves the Mohr circle to the right (state II) under conditions in which the change in horizontal effective stress is less than the change in vertical effective stress. The maximum stress difference is not sufficient to cause failure or slip. Upon repressurization, assuming no inelastic effects, the Mohr circle returns to state I. If pressurization continues so that pore pressures rise above pre-development levels the Mohr circle moves to the left, resulting in the condition for failure or slip as indicated by state III in the figure. It has been assumed in this construction that the vertical effective stress changes more rapidly than the horizontal effective stress during pore pressure increase.

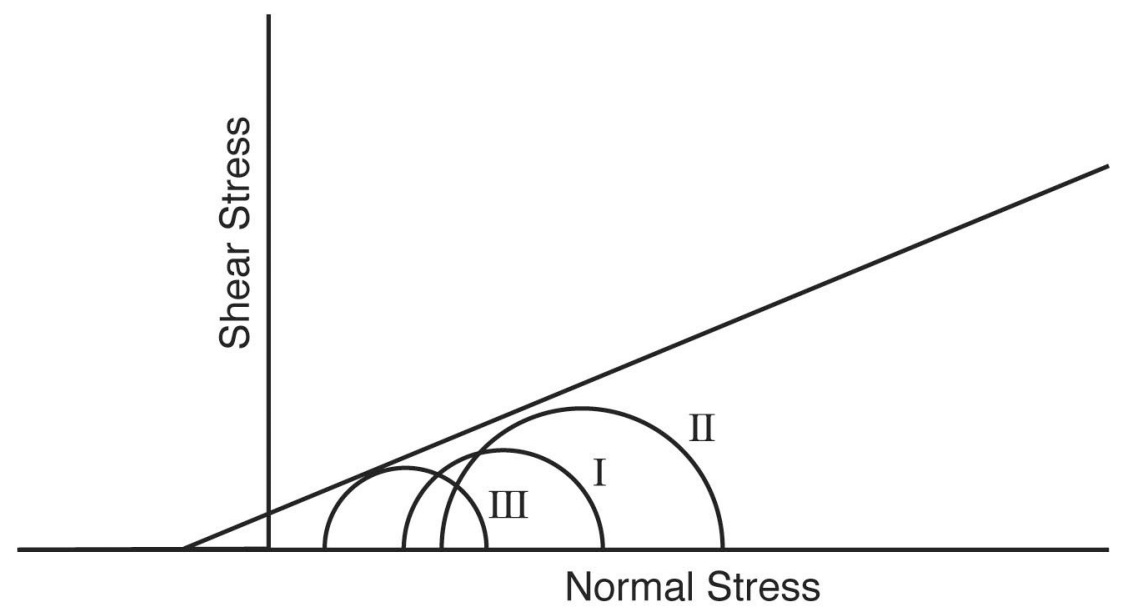

Figure 8. Mohr circles for initial (I), intermediate (II) and final (III) stress state when pore pressure first decreases (II) and then increases (III) with respect to initial conditions. Failure or slip occurs at III.

The approach outlined above can be used to make a preliminary assessment of the potential for slip on pre-existing discontinuities in the coal in the San Juan basin. Values of parameters used in the analysis are summarized in Table 1. A mean depth of 3,200 feet and an initial reservoir pressure of 1,500 psi before dewatering and methane production are assumed. The reservoir pressure is consistent with a normal hydrostatic gradient and observations in some areas of the San Juan basin. It is assumed that the maximum principal stress is vertical $\left(\mathrm{S}_{\mathrm{V}}\right)$ and the density gradient is one psi per foot of depth. For purpose 
of this calculation the in-situ stress, $\mathrm{S}_{\mathrm{hmin}} / \mathrm{S}_{\mathrm{V}}$, where $\mathrm{S}_{\mathrm{hmin}}$ is the minimum horizontal stress, is assumed to be 0.7 . The condition for slip on the discontinuity is given by a linear Mohr-Coulomb criteria with the conservative assumption the cohesion is zero. A coefficient of friction, $\mu$, of 0.6 is assumed. This value is frequently assumed in analyses of slip on faults in petroleum reservoirs (Gibson-Poole, et al, 2002, Peska and Zobach, 1995). It is also consistent with laboratory measurements of the strength of coal under confining pressures of several thousand psi (Murrell 1958).

Table 1: Slip Analysis Parameter

\begin{tabular}{|c|c|}
\hline Parameter & Value \\
\hline Mean reservoir depth & 3,200 feet \\
\hline Initial reservoir pressure & $1,500 \mathrm{psi}$ \\
\hline Post drawdown reservoir pressure & $500 \mathrm{psi}$ \\
\hline Reservoir pressure after $\mathrm{CO}_{2}$ injection & $2,000 \mathrm{psi}$ \\
\hline Poisson's ratio for coal & $0.3,0.4$ \\
\hline Coefficient of friction for slip & 0.6 \\
\hline In-situ stress ratio $\left(\mathrm{S}_{\mathrm{hmin}} / \mathrm{S}_{\mathrm{V}}\right)$ & 0.7 \\
\hline
\end{tabular}

The Mohr circle labeled by I in Figure 9 represents the initial stress conditions. It is assumed that pore pressures have equilibrated over a large area over time, so the initial major and minor principal effective stresses, $\sigma_{1}$ and $\sigma_{3}$, are given by subtracting 1500 psi from both $\mathrm{S}_{\mathrm{V}}$ and $\mathrm{S}_{\mathrm{hmin}}$. It is then assumed that reservoir pressures are drawn down to $500 \mathrm{psi}$ and there is a poroelastic effect in a finite-sized reservoir. From Figure 7, if the Poisson's ratio of the coal is 0.3 , then $\Delta \mathrm{S}_{\mathrm{hmin}}=-0.53 \Delta \mathrm{P}$ (where $\mathrm{P}$ is reservoir pressure and - refers to a decrease in P) and the Mohr circle moves to position labeled II. As seen in the figure, there is no slip. For a Poisson's ratio of $0.4, \Delta \mathrm{S}_{\mathrm{hmin}}=-0.23 \Delta \mathrm{P}$ and the Mohr circle is given by II' which is a more stable condition than that attained for Poisson's ratio of 0.3

Finally, it is assumed that $\mathrm{CO}_{2}$ injection increases reservoir pressure to 2,000 psi. Taking account of poroelastic effects and assuming a Poisson's ratio of 0.3 for the coal, the Mohr circle moves from II to III. For this case, there is still no slip on discontinuities. However, for Poisson's ratio of $0.4, \Delta \mathrm{S}_{\mathrm{hmin}}=0.23 \Delta \mathrm{P}$, 
and the Mohr circle moves from II' to III'; intersecting the criterion for slip. During repressurization more stable conditions are attained if the Poisson's ratio of the reservoir material is low.

The dip of discontinuities upon which slip would occur can be determined from the intersection of the Mohr circle with the failure criteria. The equations for the two values of $\beta$ corresponding to the points of intersection are (Jaeger and Cook 1971)

$$
\begin{array}{ll} 
& 2 \beta_{1}=\pi+\varphi-\sin ^{-1}\left[\left(\sigma_{\mathrm{m}} / \tau_{\mathrm{m}}\right) \sin \varphi\right] \\
\text { and } \quad & 2 \beta_{2}=\varphi+\sin ^{-1}\left[\left(\sigma_{\mathrm{m}} / \tau_{\mathrm{m}}\right) \sin \varphi\right] \\
\text { where } & \varphi=\tan ^{-1} \mu \\
& \sigma_{\mathrm{m}}=1 / 2\left(\sigma_{1}+\sigma_{3}\right) \\
& \tau_{\mathrm{m}}=1 / 2\left(\sigma_{1}-\sigma_{3}\right)
\end{array}
$$

For conditions represented by the circle III' in Figure 9, slip would occur on discontinuities with dips between $50^{\circ}$ and $70^{\circ}$.

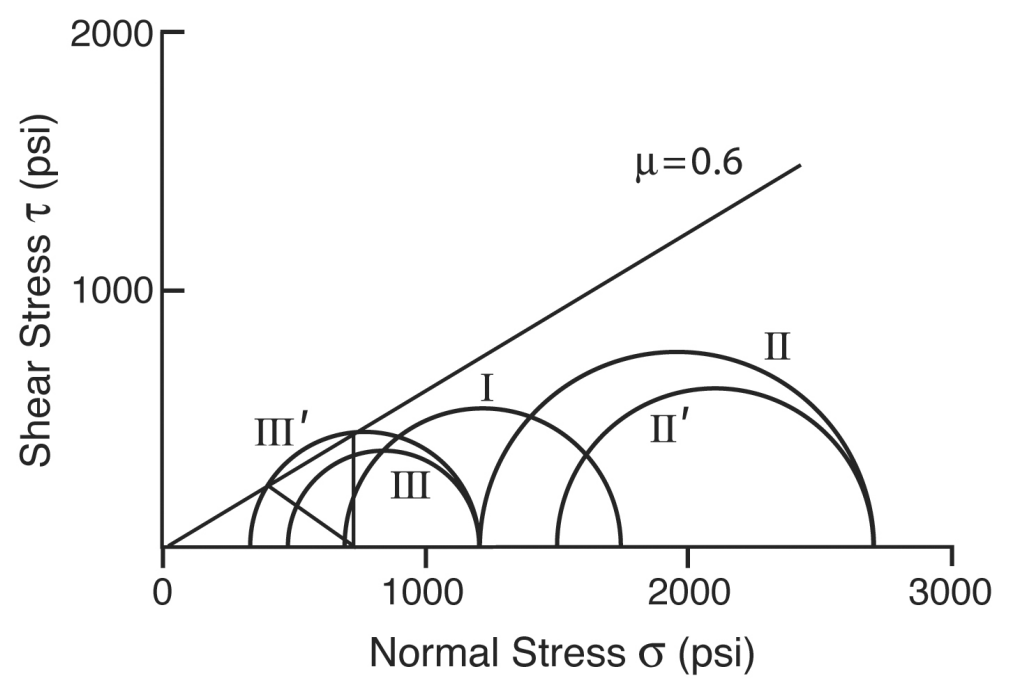

Figure 9. Mohr circles for slip on a discontinuity in a coal seam under conditions representative of the San Juan basin.

Results of these analyses are very sensitive to the in-situ stress state. The risk of slip is significantly reduced as $\mathrm{S}_{\mathrm{hmin}} / \mathrm{S}_{\mathrm{V}} \rightarrow 1$. If the stability analysis is repeated assuming $\mathrm{S}_{\mathrm{hmin}} / \mathrm{S}_{\mathrm{V}}=1$, a common assumption in 
reservoir simulation, then no slip would be predicted for any of the reservoir pressure conditions.

However, if $\mathrm{S}_{\mathrm{hmin}} / \mathrm{S}_{\mathrm{V}}=0.6$, slip is predicted even under the assumed initial reservoir pressure of 1,500 psi.

\section{Failure and Slip in the Overburden}

So far, the discussion has focused only on the risk of failure or slip within the coal seam. However, potential leakage paths require failure in slip in the bounding rock layers as well as in the coal seam. A possible, though least likely mechanism, is the propagation of a shear failure from the coal into the bounding rock. As discussed previously, fracture propagation into the bounding rock is impeded when the coal strength is less than the strength of the bounding rock.

Volumetric changes in the reservoir have an important influence on displacements in the overburden. During production, there is a volumetric decrease in the reservoir due to pore pressure reduction. The amount of volumetric decrease is a function of the compressibility of the reservoir rock and its thickness. In coal there is an added component due to shrinkage from desorption of the methane. The volumetric decrease in the reservoir causes subsidence of the overburden. On the flanks of the reservoir, bending of the overburden layers results in shear stresses which can cause failure or slip on pre-existing discontinuities. If the pore pressure distribution, and hence, volumetric deformation, in the reservoir is not uniform, shear displacements in the overburden will be introduced at places other than the flanks.

Repressurization of the reservoir causes volumetric expansion and upward displacement, or heave, in the overburden. The effect on shear displacements is to reverse the sense of motion. Thus, shear displacement on a discontinuity can move in one direction during drawdown and reverse and move in the opposite direction during injection. An example of this is shown in Figure 10. The figure shows modeled well displacements due to shear on a weak zone in the overburden above the South Belridge oil reservoir. This reservoir has undergone pressure drawdown from production and then repressurization from aggressive water injection. 


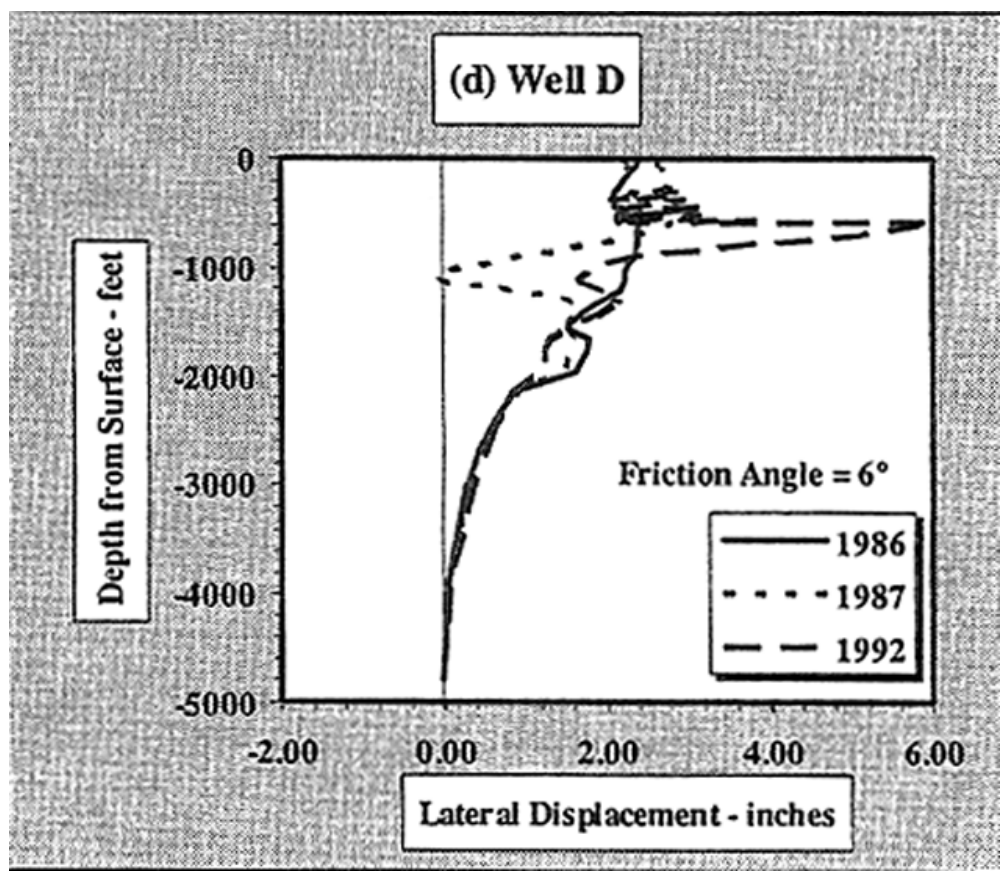

Figure 10. Numerical simulation of lateral displacement of a well in the South Belridge reservoir. Large lateral displacements at about 1,000 feet depth occur due to slip on an interface with a friction angle of $6^{\circ}$. Lateral displacements reverse between the years of 1987 and 1992 (after Hilbert at al, 1996).

An example of the development of shear displacements near the interface between the reservoir and overburden when $\mathrm{CO}_{2}$ is injected is shown in Figure 11. The figure shows results of a numerical simulation of injection of $\mathrm{CO}_{2}$ from a single well into a brine-saturated layer. The shaded region in part $b$ of the figure shows where shear stresses develop. The blue outline shows the extent of the $\mathrm{CO}_{2}$ plume. The volumetric expansion of coal with $\mathrm{CO}_{2}$ will have an additional component due to swelling associated with gas sorption. Experimental work indicates that $\mathrm{CO}_{2}$ causes more volumetric changes than methane. This will further alter the distribution of volumetric expansion resulting from repressurization. 


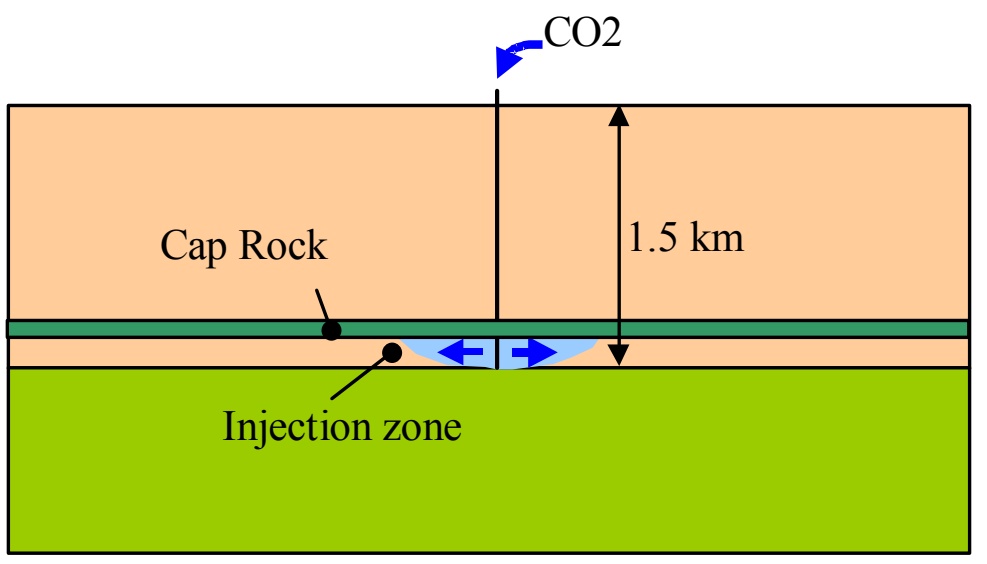

a)

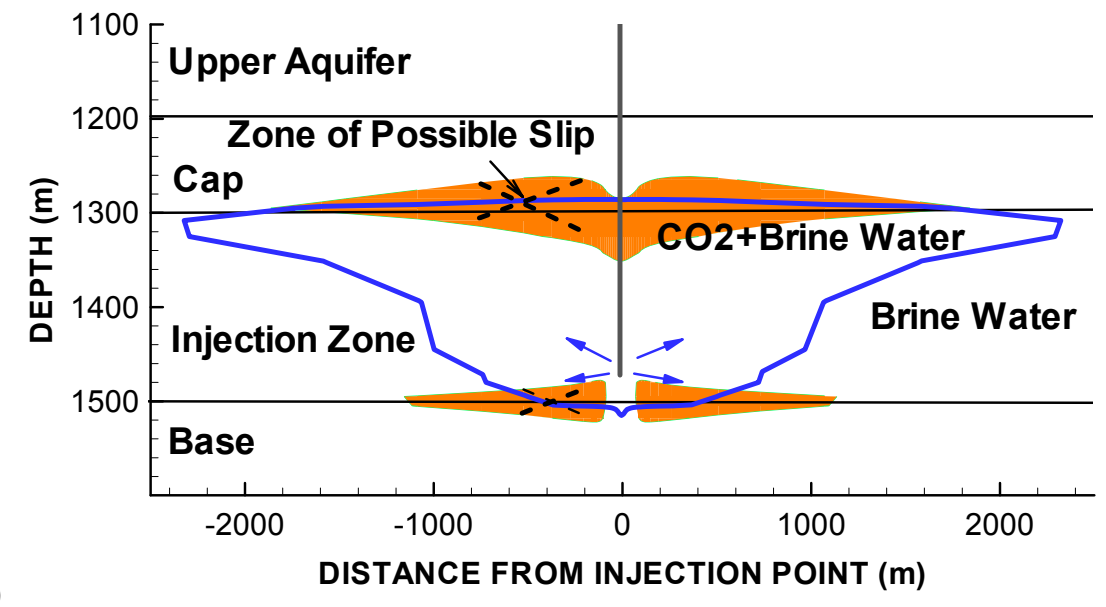

Figure 11. Results of numerical simulation of stresses and displacements due to injection of $\mathrm{CO}_{2}$ into a brine saturated formation (from Rutqvist and Tsang, 2003).

a) The model

b) Outline of plume and region where shear stresses could cause slip on discontinuities

If a pre-existing discontinuity cuts across the coal seam, model results show that slip can occur in the overburden, outside of the region of pore pressure change. Figure 12a shows a model in which there is a pressurized region between two discontinuities (“faults") dipping at $45^{\circ}$. Calculations were carried out using the coupled hydrologic/geomechanical simulator TOUGH-FLAC (Rutqvist et al, 2002). The faults were represented by "slip lines" with a friction angle of $25^{\circ}$. Figure $12 \mathrm{~b}$ shows the shear slip on the faults as a function of depth. Due to the symmetry of the problem, the sense of motion is in one direction on one 
fault and in the opposite direction on the other fault. It is seen that the magnitude of the slip is greatest within the region of pressure increase and tails off quickly outside the region.

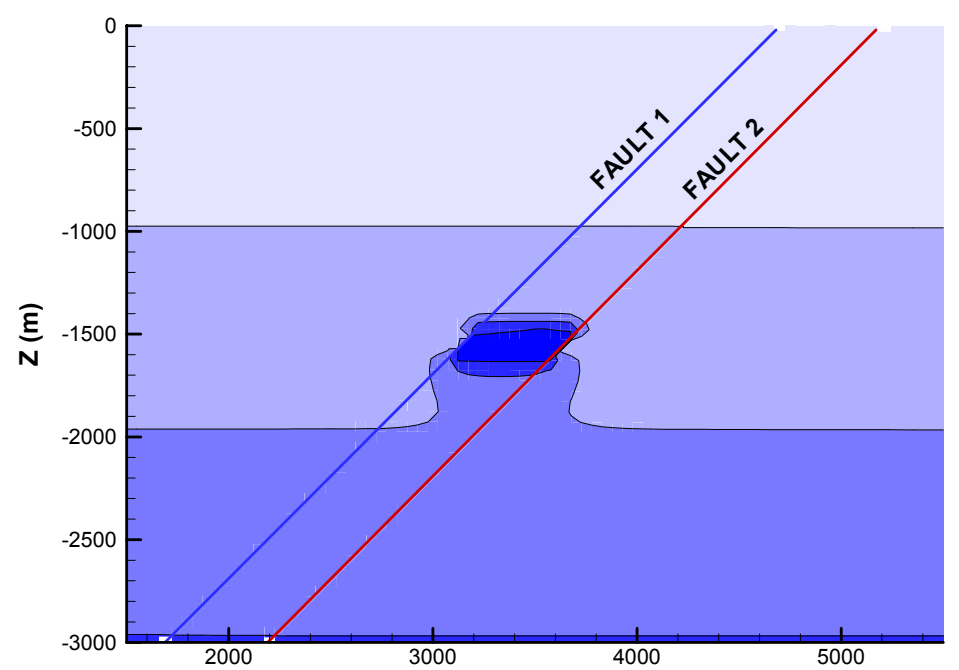

a)

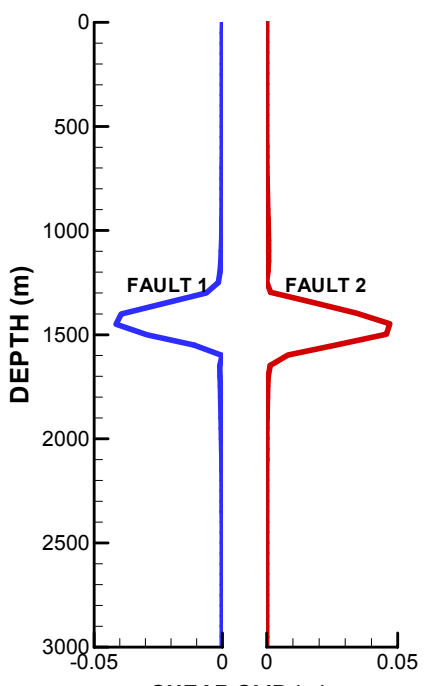

b)

Figure 12. Numerical simulation of slip on discontinuities resulting from a pressurized region

a) The model, showing a maximum pressure increase in the region of 2.6 times original pressure

b) Shear slip on the faults

Slip on pre-existing faults and other discontinuities which intersect the coal seam are viewed as a likely scenario for generation of possible leakage paths for $\mathrm{CO}_{2}$. Numerical sensitivity studies should be performed to evaluate the effects the dip and frictional properties of faults for representative coal seam pressure changes. It is important to capture coal volumetric changes due to sorption and desorption as part of these models.

While slip on pre-existing discontinuities creates a potential leakage path, further analysis is required to evaluate whether or not fluid flow will occur in conjunction with the slip. The risk of leakage will be increased if the magnitude of the slip is on the order of bed thickness. Geologic studies of fault seals have shown that fault movement which brings sand layers into contact can lead to fluid flow across faults from higher to lower pressure sands. 
The degree to which slip will increase the potential for flow along faults and discontinuities is much less well understood. Laboratory tests have shown that shearing a rock fracture in rock will increase its permeability as a result of dilatancy. Since fracture surfaces are rough, shear displacements can lead to an opening of the fracture and an increase in permeability. Less dilatancy would be expected for faults or discontinuities filled with clay gouge. The relationship between stress state, slip magnitude, fault and fracture surface geometry and changes in hydrologic properties of infilling materials is an area requiring substantial additional basic research.

\section{SUMMARY}

Geomechanical processes lead to risks of developing leakage paths for $\mathrm{CO}_{2}$ at each step in the process of developing a coal bed methane project for methane production and eventual $\mathrm{CO}_{2}$ sequestration. Though each of the risks identified in this study needs to be evaluated for specific sites, the following general conclusions have been drawn from this review:

- Conventional techniques are available to minimize risk of leaks in new well construction though additional study should be devoted to establishing best practices for the height of cement behind production casing; risk of leakage is higher for old wells converted to injectors.

- Risks of leakage is much higher for open cavity completions than for cased well completions.

- Coal properties and available technology should minimize the risk that hydrofractures, used as part of completion, will grow out of interval; techniques to monitor fracture height need further development.

- The processes of depressurization during dewatering and methane production, followed by repressurization during $\mathrm{CO}_{2}$ injection, lead to risks of leakage path formation by failure of the coal and slip on discontinuities in the coal and overburden.

- The most likely mechanism for leakage path formation is slip on pre-existing discontinuities which cut across the coal seam. Sensitivity studies need to be performed to better evaluate this risk. 
- Relationships between the amount of slip and the increase in flow (if any) along a discontinuity need to be developed.

\section{REFERENCES}

Addis MA. 1997a. Reservoir depletion and its effect on wellbore stability evaluation. International Journal of Rock Mechanics Mining Sciences, 34(3-4), p. 423.

Addis MA. 1997b. The stress-depletion response of reservoirs. SPE 38720. Proceedings of $72^{\mathrm{nd}}$ SPE Annual Technical conference and Exhibition, San Antonio, TX.

Addis MA, Choi X, Cumming J. 1998. The influence of the reservoir stress-depletion response on the lifetime considerations of well completion design. SPE 47210. Proceedings of SPE/ISRM, Trodheim, Norway.

Ahmed U. 1989. Fracture-height predictions and post-treatment measurements. Reservoir Stimulation, pp. 10-1 to -3 .

Ahmed U, Newberry BM, Cannon DE. 1985. Hydraulic fracture treatment design of wells with multiple zones. SPE 13857.

Anderson JA, Pearson CM, Abou-Sayed AS, Myers GD. 1986. Determination of fracture height by spectral gamma log analysis. SPE 15439. Proceedings of $61^{\text {th }}$ Annual Technical Conference, New Orleans, LA.

Atkinson B, Meredith P. 1987. Experimental fracture mechanics data for rocks and minerals. Fracture Mechanics of Rock, pp. 477.

Ben-Naceur K. 1989. Modeling of hydraulic fracture. Reservoir Stimulation, pp. 3-1 to 3-31.

Bland D. 1992. Coalbed methane from the Fruitland Formation, San Juan Basin, New Mexico. North Mexico Geological Society $43^{\text {rd }}$ Annual Conference. 
Gibson-Poole CM, Lang SC, Streit JE, Kraishan GM, Hillis RR. 2002. Assessing a basin's potential for geological sequestration of carbon dioxide: an example from the Mesozoic of the Petrel Sub-basin, NW Australia. Presented at Proceedings of the Petroleum Exploration Society of Australia Symposium, Perth, Western Australia.

Hilbert LB, Fredrick JT, Bruno MS, Deitrich GL, P.de Roufflignae E. 1996. Two dimensional nonlinear finite element analysis of well damage due to reservoir compaction, well to well interactions and localization. Proceedings of $2^{\text {nd }}$ North American Rock Mechanics Symposium, Montrea, Belkema, 2, pp. 1863-1870.

Jaeger JL, Cook NGW. 1971. Fundamentals of Rock Mechanics: Chapman and Hall, Ltd., pp. 67.

Murray D. 1993. Coalbed methane reservoir evaluation and completion technology. Atlas of Major Rocky Mountain Gas Reservoirs, New Mexico Bureau of Mines and Mineral Resources, pp. 88-189.

Murrell SAF. 1958. The strength of coal in triaxial compression. Presented at Proceedings of Conference Mechanical Properties Non-Metallic Brittle Materials, Butterworths, London, England.

Nolte K, Economides M. 1989. Fracturing diagnosis using pressure analysis. Reservoir Stimulation, pp. 7-1 to 7-34.

Peska P, Zoback MD. 1995. Compressive and tensile failure of inclined well bores and determination of in situ stress and rock strength. Journal of Geophysical Research, 100: pp. 12791-811.

Poulos H, Davis E. 1974. Elastic solutions for soil and rock mechanics. John Wiley \& Sons, pp. 237. 
Rutqvist J, Tsang C-F. 2003. TOUGH-FLAC: A numerical simulator for analysis of coupled thermal hydrologic mechancial processes in fractured and porous geological media under multiphase flow conditions. TOUGH Symposium, Berkeley, CA.

Rutqvist J, Wu Y-S, Tsang C-F, Bodvarsson G. 2002. A modeling approach for analysis of coupled multi-phase fluid flow, heat transfer, and deformation in fractured porous rock. International Journal of Rock Mechanics Mining Sciences, 39: pp. 429-442.

Streit JE, Hillis RR. 2002. Estimating fluid pressures that can induce reservoir failure during hydrocarbon depletion. Presented at SPE 78226. SPE/ISRM Rock Mechanics Conference, Irving, TX.

Terzaghi K, Richart FE. 1952. Stresses in rock about cavities. Geotechnique, 3: pp. 57-90.

Teufel LW, Rhett DW, Farrell HE. 1991. Effect of reservoir depletion and pore pressure drawdown on in situ stress and deformation in the Ekofisk field, North Sea. Proceedings of $32^{\text {nd }}$ US Rock Mechanics Symposium, Norman, OK, pp. 63-72.

Touloukian Y, Judd W, Roy R. 1981. Physical properties of rocks and minerals. McGraw-Hill, pp. $132-44$. 